Supporting Information

\title{
Effects of Solvent Dielectric Constant and Viscosity on Two Rotational Relaxation Paths of Excited 9-(Dicyanovinyl) Julolidine
}

\author{
Songqiu Yang, Keli Han*
}

State Key Laboratory of Molecular Reaction Dynamics, Dalian Institute of Chemical Physics, Chinese Academy of Sciences, Dalian, 116023, China.

\section{Contents:}

Table S1. The dielectric constant and viscosity of three solvents.

Table S2. The vertical excited energies (VEEs in $\mathrm{nm}$ ) of DCVJ at ground state optimized geometry (GS opt) and the first excited state optimized geometry are calculated at TDDFT, B3LYP/6-31G(d,p) level. The experimental results are shown in brackets.

Table S3. The $\mathrm{S}_{1}$ optimized geometries of Twist 1 DCVJ was obtained at TD-B3LYP/6$31 \mathrm{G}(\mathrm{d}, \mathrm{p})$ level. The Cartesian coordinates are shown below:

Figure S1. The optimized geometries of DCVJ in three solvents were calculated at TDDFT//B3LYP/6-31G (d, p) level.

Figure S2. The NBO charge distributions of DCVJ at GS optimized state and $\mathrm{S}_{1}$ optimized state. It were calculated at (TD-)B3LYP/6-31G (d, p) level, IEFPCM model was considered in acetonitrile. The major charge changes are labeled at, N7, C4 and C15. There is a small charge transfer from N7(+0.004) and $\mathrm{C} 4(+0.003)$ to $\mathrm{C} 15(-0.009)$ from GS to S1 optimized state.

Figure S3. The PESs of GS, $\mathrm{S}_{1}$ and $\mathrm{S}_{2}$.

Figure S4 (a) The femtosecond time-resolved transient absorption spectra of DCVJ in the n-Hexane are shown; (b) The time evolution spectra; (c) 3 lines come from the global fitting results.

Figure S5. (a) The femtosecond time-resolved transient absorption spectra of DCVJ in the EG are shown. (b) The time evolution spectra; (c) 3 lines come from the global fitting results.

Scheme S1. The excited state decay kinetic model for DCVJ.

Details about the excited state decay kinetic model for DCVJ. 
Table S1. The dielectric constant and viscosity of three solvents.

\begin{tabular}{lll}
\hline & Dielectric constant, $\boldsymbol{\varepsilon}$ & Viscosity, $\boldsymbol{\eta}$ \\
\hline n-Hexane (nHex) & 1.88 & 0.33 \\
\hline Acetonitrile (MeCN) & 35.7 & 0.37 \\
Ethylene Glycol (EG) & 40.2 & 19.9 \\
\hline
\end{tabular}

Table S2. The vertical excited energies (VEEs in $\mathrm{nm}$ ) of DCVJ at ground state optimized geometry (GS opt) and the first excited state optimized geometry are calculated at TDDFT, B3LYP/6-31G(d,p) level. The experimental results are shown in brackets.

\begin{tabular}{llll}
\hline Structure & nHex(nm) & MeCN(nm) & EG(nm) \\
\hline GS opt & $394(432)$ & $404(457)$ & $407(466)$ \\
S $_{\mathbf{1}}$ opt & $848(442)^{*}$ & $455(496)$ & $456(500)$ \\
\hline
\end{tabular}

*the structure of DCVJ here is a twisted geometry which far from the emission state. 
Table S3. The $\mathrm{S}_{1}$ optimized geometries of Twist1 DCVJ was obtained at TD-B3LYP/6$31 \mathrm{G}(\mathrm{d}, \mathrm{p})$ level. The Cartesian coordinates are shown below:

$\begin{array}{llll}\text { C } & -1.25575200 & 0.02611400 & -0.80993000 \\ \text { C } & -0.46752900 & 1.19446700 & -0.85751300 \\ & & & \\ \text { C } & 0.88218600 & 1.20205400 & -0.55976500 \\ \text { C } & 1.50757800 & -0.03631500 & -0.19002700 \\ \text { C } & 0.73725700 & -1.24791000 & -0.15381800 \\ \text { C } & -0.60703500 & -1.17924900 & -0.46146700 \\ \text { N } & 2.83585700 & -0.06073700 & 0.13304400 \\ \text { C } & 3.55717200 & -1.30742800 & 0.42481500 \\ \text { C } & 2.87339800 & -2.53252400 & -0.16726600 \\ \text { C } & 1.39981900 & -2.54273200 & 0.24081800 \\ \text { C } & 1.69914100 & 2.46750700 & -0.59883300 \\ \text { C } & 2.80583700 & 2.41021700 & 0.45496400 \\ \text { C } & 3.64856400 & 1.15949000 & 0.24208200 \\ \text { C } & -2.72016700 & 0.08746500 & -1.08057800 \\ \text { C } & -3.62568600 & 0.08392300 & 0.03311700 \\ \text { C } & -4.99872700 & -0.18853800 & -0.15457000\end{array}$




\begin{tabular}{|c|c|c|c|}
\hline $\mathrm{N}$ & -6.13305900 & -0.42495700 & -0.33022400 \\
\hline $\mathrm{C}$ & -3.19937900 & 0.39438300 & 1.34265400 \\
\hline $\mathrm{N}$ & -2.78516100 & 0.64954700 & 2.41089000 \\
\hline $\mathrm{H}$ & -0.96010700 & 2.12452400 & -1.12006900 \\
\hline $\mathrm{H}$ & -1.20331600 & -2.08497800 & -0.41612300 \\
\hline $\mathrm{H}$ & 3.63906500 & -1.39994700 & 1.51791200 \\
\hline $\mathrm{H}$ & 4.57383300 & -1.19038000 & 0.03519600 \\
\hline $\mathrm{H}$ & 3.39167300 & -3.42872000 & 0.18496100 \\
\hline $\mathrm{H}$ & 2.96136300 & -2.51069900 & -1.25952900 \\
\hline $\mathrm{H}$ & 1.32001100 & -2.67829400 & 1.32917500 \\
\hline $\mathrm{H}$ & 0.86911500 & -3.38282300 & -0.21482500 \\
\hline $\mathrm{H}$ & 1.04776600 & 3.33036600 & -0.43973900 \\
\hline $\mathrm{H}$ & 2.14721100 & 2.59206600 & -1.59596900 \\
\hline $\mathrm{H}$ & 2.36526200 & 2.39177800 & 1.45777100 \\
\hline $\mathrm{H}$ & 3.45763500 & 3.28652300 & 0.39834900 \\
\hline $\mathrm{H}$ & 4.34987700 & 1.00632300 & 1.06897100 \\
\hline $\mathrm{H}$ & 4.24783100 & 1.24616500 & -0.67660800 \\
\hline $\mathrm{H}$ & -3.05074200 & -0.39442500 & -1.99353600 \\
\hline
\end{tabular}




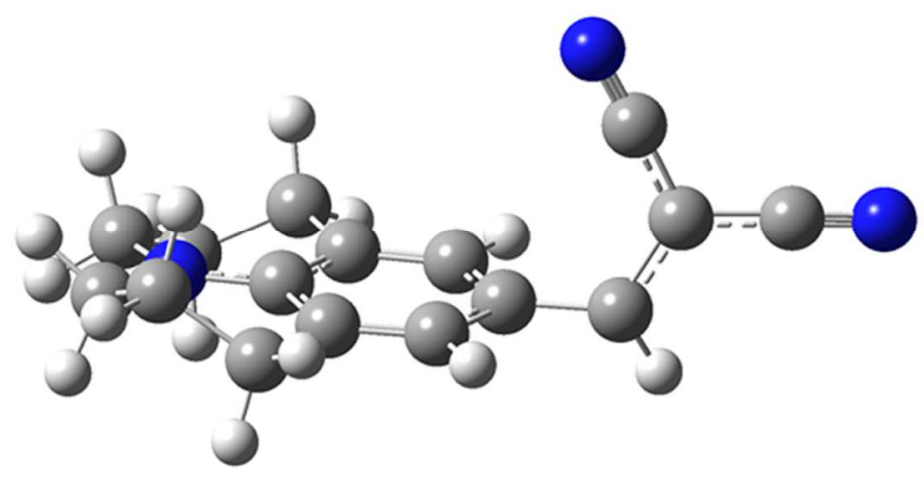

\section{n-Hexane}
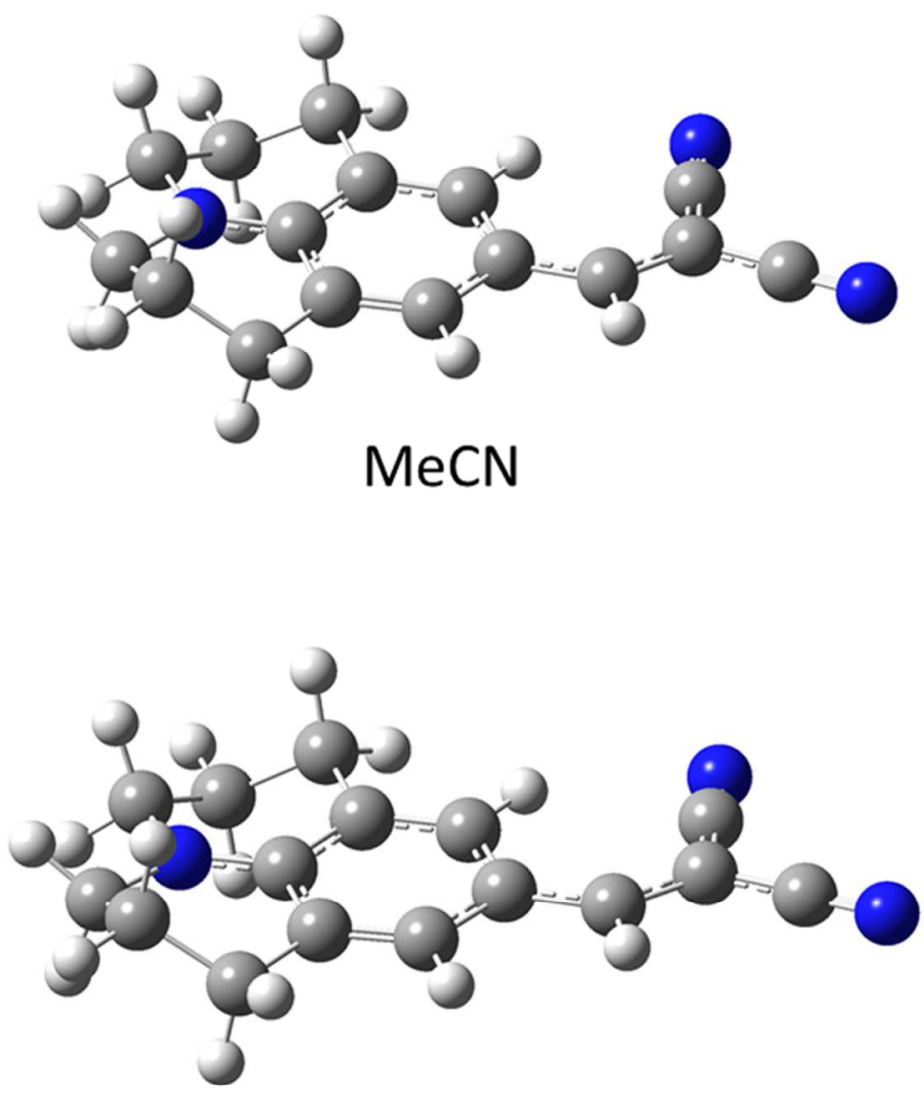

EG

Figure S1. The optimized geometries of DCVJ in three solvents were calculated at TDDFT//B3LYP/6-31G (d, p) level. 


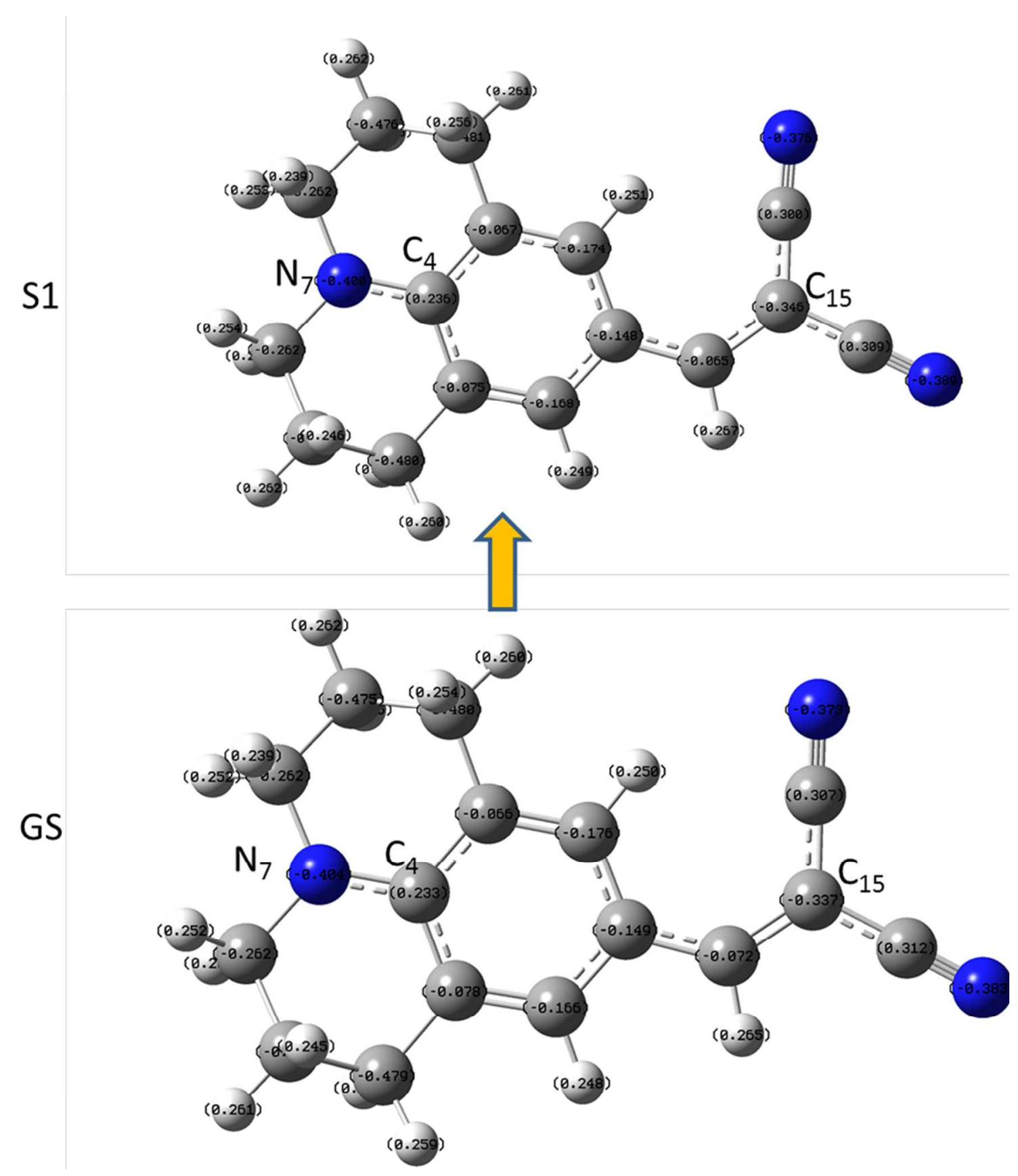

Figure S2. The NBO charge distributions of DCVJ at GS optimized state (bottom) and $\mathrm{S}_{1}$ optimized state (upper). It were calculated at (TD-)B3LYP/6-31G (d, p) level, IEFPCM model was considered in acetonitrile. The major charge changes are labeled at, $\mathrm{N}_{7}, \mathrm{C}_{4}$ and $\mathrm{C}_{15}$. There is a small charge transfer from $\mathrm{N}_{7}(+0.004)$ and $\mathrm{C}_{4}(+0.003)$ to $\mathrm{C}_{15}(-0.009)$ from $\mathrm{GS}$ to $\mathrm{S}_{1}$ optimized state. 


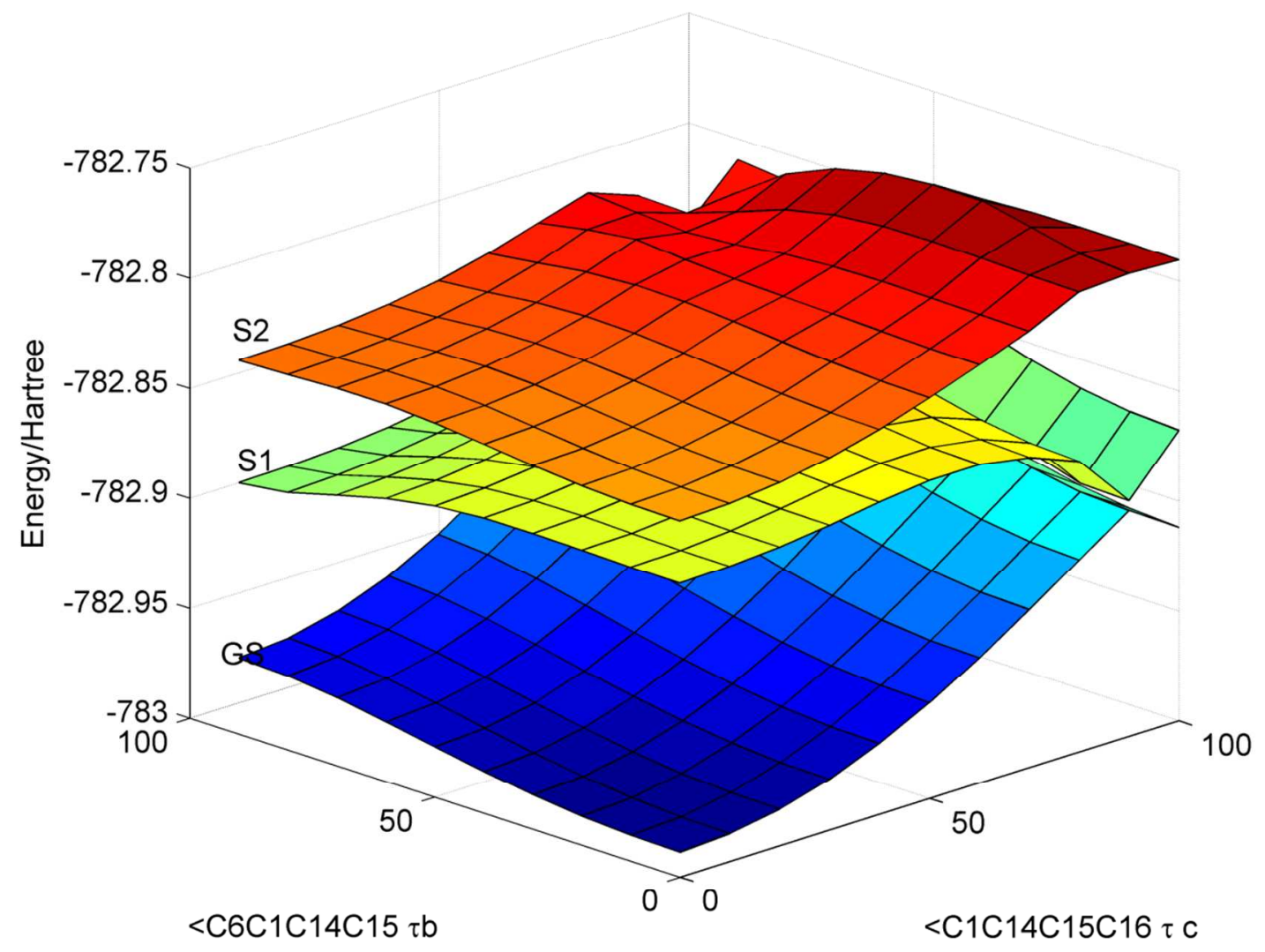

Figure S3. The PESs of GS, $\mathrm{S}_{1}$ and $\mathrm{S}_{2}$. 
(a)

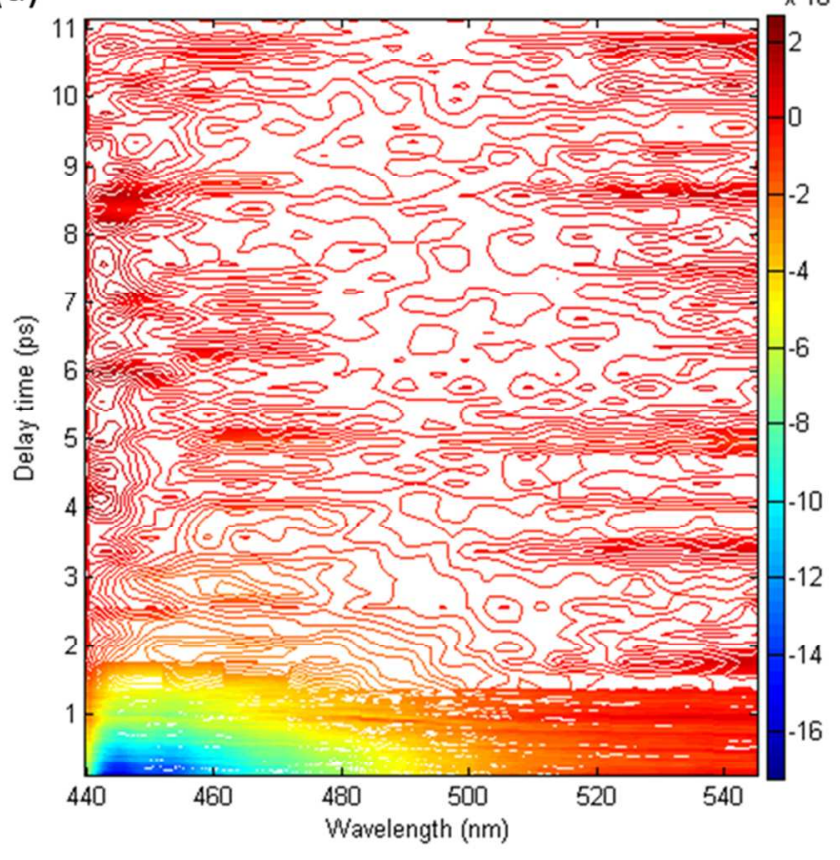

(b)

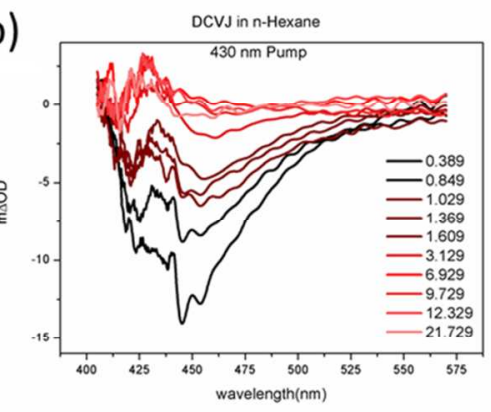

(c)

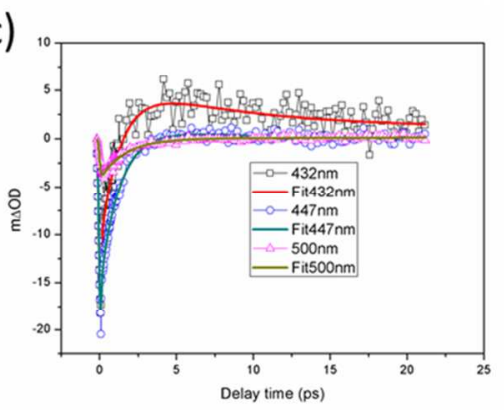

Figure S4 (a) The femtosecond time-resolved transient absorption spectra of DCVJ in the n-Hexane are shown; (b) The time evolution spectra; (c) 3 lines come from the global fitting results. 
(a)

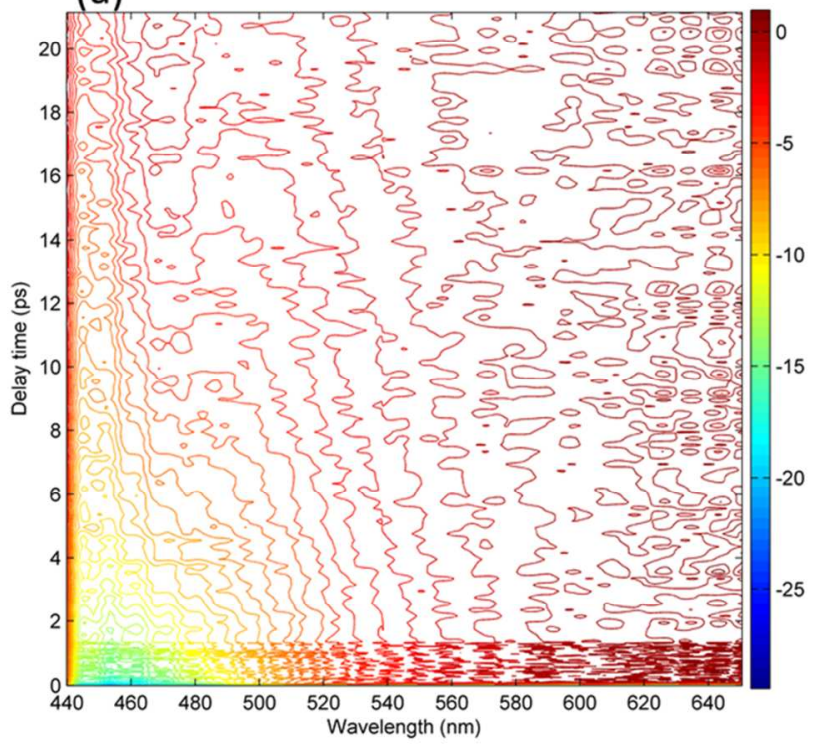

(b)

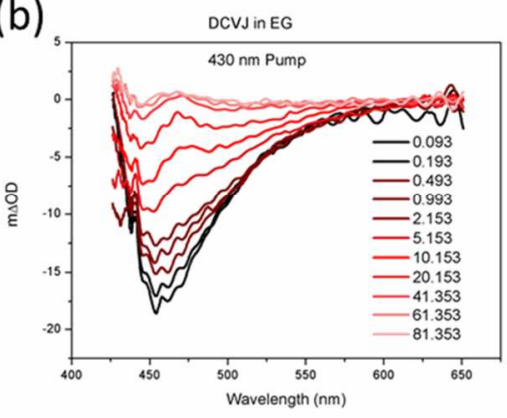

(c)

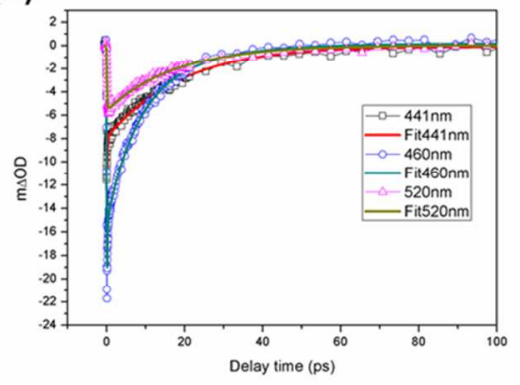

Figure S5. (a) The femtosecond time-resolved transient absorption spectra of DCVJ in the EG are shown. (b) The time evolution spectra; (c) 3 lines come from the global fitting results. 


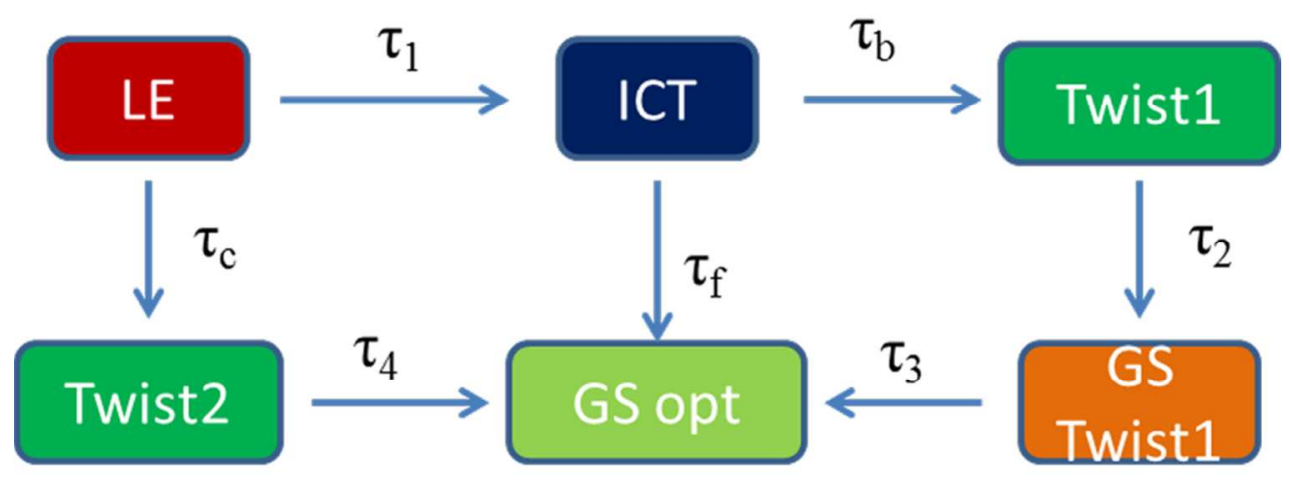

Scheme S1. The excited state decay kinetic model for DCVJ.

The kinetic model shown in Scheme S1 is used here for DCVJ. The initial populations are at local excited (LE) state, then, two paths are branched. One path is the rotation of $\mathrm{C}_{1} \mathrm{C}_{14} \mathrm{C}_{15} \mathrm{C}_{16}, \tau_{\mathrm{c}}$ to Twist 2 geometry, then go back to the ground state optimized geometry via a conical intersection. Herein, $\tau_{\mathrm{c}}$ includes the decay from LE to twist 2 and then to GS optimization state. $\tau_{4}$ is included in $\tau_{\mathrm{c}}$ to simply the kinetic model in the text for it is a no-barrier vibrational relaxation. The other path is LE to ICT relaxation. This ICT state is believed as the emission state of DCVJ. The lifetime, $\tau_{\mathrm{f}}$, is $3.6 \mathrm{~ns}$ according to the previous report ${ }^{1}$. The rotation of dihedral angle $\mathrm{C}_{6} \mathrm{C}_{1} \mathrm{C}_{14} \mathrm{C}_{15}, \tau_{\mathrm{b}}$ takes place at ICT state, which leads the populations to Twist 1 geometry. After a lifetime $\tau_{2}$ at Twist1, the populations go back to Twistl ground state. Then, go back to the ground state optimized geometry. The experimental results show that the Twist 1 has a lifetime $\tau_{2} \sim 10 \mathrm{ps}$, which is longer than $\tau_{\mathrm{c}}$. So, the faster rate constant obtained from the recovery bleaching signal should be $\tau_{\mathrm{c}}$ (including $\tau_{4}$ ). The other lifetimes are easily obtained, $\tau_{1}$ is obtained from the decay of LE signal, $\tau_{\mathrm{b}}$ is obtained from the decay of emission state and increase of Twist1 state, $\tau_{2}$ is obtained from the decay of Twist1. The $\tau_{2}$ for DCVJ in EG was not obtained due to the low concentration of Twist1, for $\tau_{\mathrm{b}}>\tau_{2}$. 


\section{References:}

(1) Loutfy, R. O.; Arnold, B. A. J. Phys. Chem. 1982, 86, 4205. 